\title{
JURISDICCIÓN VOLUNTARIA Y PERSONAS CON DISCAPACIDAD ${ }^{1}$
}

\author{
Non-Contentious Jurisdiction \\ and Disabled People
}

\author{
FRANCISCO JAVIER VIEIRA MORANTE \\ Tribunal Superior de Justicia de Madrid \\ fjvm1@madrid.org
}

Cómo citar/Citation

Vieira Morante, F. J. (2016).

Jurisdicción voluntaria y personas con discapacidad.

Derecho Privado y Constitución, 30, 371-385.

doi: http://dx.doi.org/10.18042/cepc/dpc.30.09

(Recepción: 10/06/2016; aceptación después de la revisión: 06/10/2016; publicación: 17/11/2016)

\section{Resumen}

La protección de las personas con discapacidad se ha ido realizando paulatinamente en nuestra legislación, mediante su adaptación a los criterios establecidos en la Convención de las Naciones Unidas sobre los Derechos de las Personas con Discapacidad. Constituye el último impulso en esta dirección la Ley de Jurisdicción Voluntaria aprobada por Ley 15/2015, de 2 de julio. Tanto en sus normas comunes como en los concretos expedientes de jurisdicción voluntaria, singularmente en ma-

1 Presentado al Seminario sobre Constitución y Jurisdicción Voluntaria, organizado por el Consejo General del Notariado y la revista Derecho Privado y Constitución, celebrado el 24 de mayo de 2016 en la sede del colegio Notarial de Madrid. 
teria de personas y de familia, se garantiza la defensa de los menores o de las personas con capacidad modificada judicialmente, término que sustituye a los de incapaz o incapacitación. Asimismo se analiza especialmente la intervención judicial en los internamientos urgentes en centros psiquiátricos.

\section{Palabras clave}

Personas con capacidad modificada judicialmente; internamiento involuntario; protección de patrimonios.

\section{Abstract}

Disabled people protection have been gradually protected in our legislation, through its adaptation to the established criteria of the United Nations Convention on Rights of Persons with Disabilities. The non-contentious jurisdiction law its the last impulse on this direction, this law was passed the 2 th of July and is know as Ley $15 / 2015$, de 2 de julio. Not only in the common regulation but also in the specific non-contentious jurisdiction proceedings there is a guarantee for the defence of underage or people with judicialy modified capacity, ar term used in substitution of disabled people. Its important to mention that this regulation enhaces the protection of people and families. Likewise it specialy analizes the judiciary intervention the urgent detentions in psychiatric placements.

\section{Keywords}

People with judicialy modified capacity, voluntary commitment, heritage protection. 
El art. 9.2 de la Constitución establece que «corresponde a los poderes públicos promover las condiciones para que la libertad y la igualdad del individuo y de los grupos en que se integra sean reales y efectivas; remover los obstáculos que impidan o dificulten su plenitud y facilitar la participación de todos los ciudadanos en la vida política, económica, cultural y social».

Por otro lado, el art. 14 de la misma Constitución establece que «los españoles son iguales ante la ley, sin que pueda prevalecer discriminación alguna por razón de nacimiento, raza, sexo, religión, opinión o cualquier otra condición o circunstancia personal o social».

Y, en relación con las personas con discapacidad, el art. 49 de la propia Constitución dispone que «los poderes públicos realizarán una política de previsión, tratamiento, rehabilitación e integración de los disminuidos físicos, sensoriales y psíquicos, a los que prestarán la atención especializada que requieran y los ampararán especialmente para el disfrute de los derechos que este título otorga a todos los ciudadanos».

En cumplimiento de estos preceptos constitucionales, la especial situación de las personas con discapacidad determinó la publicación de la Ley 41/2003, de 18 de noviembre, de protección patrimonial de las personas con discapacidad, que tuvo por objeto, como señala su exposición de motivos, ordenar los medios necesarios para que la minusvalía que padecen no les impidiera el disfrute de los derechos que a todos los ciudadanos reconocen la Constitución y las leyes, logrando así que la igualdad entre tales personas y el resto de los ciudadanos sea real y efectiva.

Se centró esa ley en la protección del patrimonio de las personas con discapacidad, al considerar que uno de los elementos que más repercuten en el bienestar de las personas con discapacidad es la existencia de medios económicos a su disposición, suficientes para atender las específicas necesidades vitales de los mismos. El objeto inmediato de esa ley fue, pues, la regulación de una masa patrimonial, el patrimonio especialmente protegido de las personas con discapacidad, la cual queda inmediata y directamente vinculada a la satisfacción de las necesidades vitales de una persona con discapacidad, favoreciendo la constitución de este patrimonio y la aportación a título gratuito de bienes y derechos a la misma. Configuró así este patrimonio como un "patrimonio de destino", en consideración a que las distintas aportaciones al mismo tienen como finalidad la satisfacción de las necesidades vitales de sus titulares. 
Para ello, restringió los beneficiarios de este patrimonio, exclusivamente, a las personas con discapacidad afectadas por unos determinados grados de minusvalía - personas afectadas por una minusvalía psíquica igual o superior al 33\%, o afectadas por una minusvalía física o sensorial igual o superior al $65 \%$ - y ello con independencia de que concurran o no en ellas las causas de incapacitación judicial contempladas en el art. 200 del Código Civil y de que, concurriendo, tales personas hayan sido o no judicialmente incapacitadas.

Aspecto fundamental del contenido de la ley 41/2003 es el de la supervisión de la administración del patrimonio protegido de las personas con discapacidad.

El primer aspecto que destaca de esta supervisión es que el constituyente puede establecer las reglas de supervisión y fiscalización de la administración del patrimonio que considere oportunas.

En segundo lugar, la supervisión institucional del patrimonio protegido corresponde al Ministerio Fiscal, respecto del cual se prevén dos tipos de actuaciones:

a) una supervisión permanente y general de la administración del patrimonio protegido, a través de la información que, periódicamente, el administrador debe remitirle.

b) Una supervisión esporádica y concreta, ya que cuando las circunstancias concurrentes en un momento determinado lo hicieran preciso, el Ministerio Fiscal puede — de oficio o a solicitud de cualquier persona - solicitar del juez la adopción de cualquier medida que se estime pertinente en beneficio de la persona con discapacidad. Igualmente, el Ministerio Fiscal será oído en todas las actuaciones judiciales que afecten al patrimonio protegido, aunque no sean instadas por él.

Por otro lado, la ley crea la Comisión de Protección Patrimonial de las Personas con Discapacidad, cuya función básica es ser un órgano externo de apoyo, auxilio y asesoramiento del Ministerio Fiscal en el ejercicio de sus funciones, sin perjuicio de las demás que reglamentariamente pudieran atribuírsele.

Habiendo supuesto un gran avance este régimen de protección patrimonial de las personas discapacitadas, constituyó un nuevo hito la Convención de las Naciones Unidas sobre los Derechos de las Personas con Discapacidad, hecha en Nueva York el 13 de diciembre de 2006, cuyo instrumento de ratificación de España se realizó el 23 de noviembre de 2007 (BOE de 21 de abril de 2008). Esta Convención considera a las personas con discapacidad como sujetos titulares de derechos, estando los poderes públicos obligados a garantizar que el ejercicio de esos derechos sea pleno y efectivo. La adaptación normativa en España a esta Convención, que se realizó por Ley 26/2011, de 
1 de agosto, supera el modelo del art. 49 de la Constitución, que denomina «médico», asumiendo la perspectiva social y de derechos y capacidades, que configura la discapacidad como un complejo conjunto de condiciones, muchas de las cuales están originadas o agravadas por el entorno social.

El penúltimo escalón en el reconocimiento y protección de las personas con discapacidad ha sido el Texto refundido de la ley general de derechos de las personas con discapacidad y de su inclusión social, aprobado por Real Decreto Legislativo 1/2013, de 29 de noviembre. En su labor de refundición, regularización, aclaración y armonización normativa (fundamentalmente en relación a la Ley 13/1982, de 7 de abril, de integración social de las personas con discapacidad; la Ley 51/2003, de 2 de diciembre, de igualdad de oportunidades, no discriminación y accesibilidad universal de las personas con discapacidad, y la Ley 49/2007, de 26 de diciembre, de infracciones y sanciones en materia de igualdad de oportunidades no discriminación), revisa los principios legislativos conforme a lo previsto en la citada Convención Internacional. Define este texto refundido la discapacidad como «situación que resulta de la interacción entre las personas con deficiencias previsiblemente permanentes y cualquier tipo de barreras que limiten o impidan su participación plena y efectiva en la sociedad, en igualdad de condiciones con las demás». Conforme a esta definición, considera "personas con discapacidad a aquellas que presentan deficiencias físicas, mentales, intelectuales o sensoriales, previsiblemente permanentes que, al interactuar con diversas barreras, puedan impedir su participación plena y efectiva en la sociedad, en igualdad de condiciones con los demás». Dedica un título específico a los derechos de las personas con discapacidad, entre los que reconoce los siguientes: a la igualdad, a la protección de la salud, a la atención integral, a la educación, a la vida independiente, al trabajo, a la protección social, y de participación en los asuntos públicos, así como otro título al derecho a la igualdad de oportunidades y no discriminación. Y también se reconoce expresamente que el ejercicio de los derechos de las personas con discapacidad se realizará de acuerdo con el principio de libertad en la toma de decisiones.

Y ha sido la nueva Ley de Jurisdicción Voluntaria (LJV), aprobada por Ley 15/2015, de 2 de julio, el último impulso para el amparo de las personas discapacitadas.

Una de sus finalidades ha sido su adaptación a la Convención de las $\mathrm{Na}-$ ciones Unidas sobre los Derechos de las Personas con Discapacidad, en relación a la nueva terminología, en la que se abandona el empleo de los términos de «incapaz» o «incapacitación», y se sustituyen por la referencia a las personas cuya capacidad está modificada judicialmente.

Esta LJV constituye un indudable avance. Dentro de las normas comunes en materia de tramitación de los expedientes de jurisdicción voluntaria 
-a las que dedica su título I- se preocupa de garantizar, a través de los medios y apoyos necesarios, la intervención de las personas con discapacidad en la comparecencia en términos que les sean accesibles y comprensibles (art. 18.2), cuya celebración prevé como regla general (arts. 17), salvo que no fuera necesaria la práctica de prueba y el juez o secretario (ahora letrado de la Administración de Justicia, nueva denominación establecida por la Ley Orgánica $7 / 2015$, de 21 de julio) no consideraran necesaria la celebración de la comparecencia para la mejor resolución del expediente. Con la misma finalidad de dar una adecuada protección a personas vulnerables, prevé en el mismo art. 18 que el juez o el letrado de la Administración de Justicia puedan acordar que «la audiencia del menor o persona con capacidad modificada judicialmente se practique en acto separado, sin interferencias de otras personas, pudiendo asistir el Ministerio Fiscal». Y prevé que, en todo caso, se garantice «que puedan ser oídos en condiciones idóneas, en términos que les sean accesibles, comprensibles y adaptados a su edad, madurez y circunstancias, recabando el auxilio de especialistas cuando ello fuera necesario», así como que esa exploración sea grabada en soporte audiovisual, siempre que sea posible.

En cuanto a la resolución del expediente de jurisdicción voluntaria, por el juez o el letrado de la Administración de Justicia prevé también que «cuando el expediente afecte a los intereses de un menor o persona con capacidad modificada judicialmente, la decisión se podrá fundar en cualesquiera hechos de los que se hubiese tenido conocimiento como consecuencia de las alegaciones de los interesados, las pruebas o la celebración de la comparecencia, aunque no hubieran sido invocados por el solicitante ni por otros interesados» (art. 19.2).

Ya en relación a concretos expedientes de jurisdicción voluntaria en materia de personas — a los que dedica la LJV su título II-, valora especialmente el interés del menor o de la persona con capacidad modificada judicialmente en la determinación de la filiación (art. 26), en los expedientes de tutela, curatela y guarda de hecho (art. 45.2) .

Los expedientes para comparecer en juicio o para el nombramiento de defensor judicial, contemplados en la LJV, van dirigidos a garantizar la defensa de los menores o de las personas con capacidad modificada judicialmente, singularmente en los casos de conflictos de intereses con sus representantes legales o su curador, o cuando estos no puedan ejercer la defensa de aquéllos, por estar ausentes, negarse a ejercerla, o estar imposibilitados de hecho (art. 27).

También esta LJV completa la protección del patrimonio de personas con discapacidad que realiza la Ley 41/2003, antes mencionada, regulando un expediente, que sólo puede promover el Ministerio Fiscal y que será resuelto en interés de la persona con discapacidad, aplicable con las siguientes finalidades: 
a) la constitución del patrimonio protegido de las personas con discapacidad o aprobación de las aportaciones al mismo cuando sus progenitores, tutor o curador se negaren injustificadamente a prestar el consentimiento o asentimiento a ello.

b) El nombramiento de su administrador cuando no se pudiera realizar conforme al título de constitución.

c) El establecimiento de exenciones a la exigencia de obtener por el administrador de la autorización o aprobación judicial para la realización de actos de disposición, gravamen u otros, que se refieran a los bienes y derechos integrantes del patrimonio protegido de las personas con discapacidad.

d) La sustitución del administrador, el cambio de las reglas de administración, el establecimiento de medidas especiales de fiscalización, la adopción de cautelas, la extinción del patrimonio protegido o cualquier otra medida de análoga naturaleza que sea necesaria tras la constitución del patrimonio protegido.

En relación con la protección del derecho al honor, a la intimidad y a la propia imagen del menor o persona con capacidad modificada judicialmente, los arts. 59 y 60 de la LJV regulan un expediente para la obtención de autorización judicial del consentimiento a las intromisiones legítimas en el ámbito de protección delimitado por el art. 3 de la Ley Orgánica 1/1982, de 5 de mayo, de protección civil del derecho al honor, a la intimidad personal y familiar y a la propia imagen, cuando el Ministerio Fiscal se hubiera opuesto al consentimiento otorgado por el representante legal de un menor o persona con capacidad modificada judicialmente. También la resolución de este expediente por el juez debe hacerse «en atención al interés superior del menor o persona con la capacidad modificada judicialmente».

A la autorización o aprobación judicial para la realización de actos de disposición, gravamen u otros que se refieran a los bienes y derechos de menores y personas con capacidad modificada judicialmente se refieren los arts. 61 a 66 de la LJV. Se aplica a todos los casos en que, conforme al Código Civil o la Ley $41 / 2003$, de 18 de noviembre, de protección patrimonial de las personas con discapacidad, el representante legal del menor o persona con capacidad modificada judicialmente o el administrador de un patrimonio protegido necesite autorización o aprobación judicial para la validez de actos de disposición, gravamen u otros que se refieran a sus bienes o derechos o al patrimonio protegido, salvo que hubiera establecida una tramitación específica. Y la resolución por el juez de la solicitud debe hacerse «teniendo en cuenta la justificación ofrecida y valorando su conveniencia a los intereses del menor o persona con capacidad modificada judicialmente». 
Entre los expedientes de jurisdicción voluntaria en materia de familia regulados en el título III de la LJV — afectan a las personas con discapacidad las medidas de protección relativas al ejercicio inadecuado de la potestad de guarda o de administración de los bienes del menor o persona con capacidad modificada judicialmente, contempladas en la sección $3^{\text {a }}$ del capítulo II (arts., 87 a 89). Concretamente se refiere a la adopción de las medidas de protección de los menores y de las personas con capacidad modificada judicialmente establecidas en el art. 158 del Código Civil². Si el juez estimare procedente la adopción de medidas, resolverá lo que corresponda designando persona o institución que, en su caso, haya de encargarse de la custodia del menor o persona con capacidad modificada judicialmente, adoptará las medidas procedentes en el caso confor-

2 Art. 158 del Código Civil:

El juez, de oficio o a instancia del propio hijo, de cualquier pariente o del Ministerio Fiscal, dictará:

1. Las medidas convenientes para asegurar la prestación de alimentos y proveer a las futuras necesidades del hijo, en caso de incumplimiento de este deber, por sus padres. 2. Las disposiciones apropiadas a fin de evitar a los hijos perturbaciones dañosas en los casos de cambio de titular de la potestad de guarda.

3. Las medidas necesarias para evitar la sustracción de los hijos menores por alguno de los progenitores o por terceras personas y, en particular, las siguientes:

a) prohibición de salida del territorio nacional, salvo autorización judicial previa.

b) Prohibición de expedición del pasaporte al menor o retirada del mismo si ya se hubiere expedido.

c) Sometimiento a autorización judicial previa de cualquier cambio de domicilio del menor.

4. La medida de prohibición a los progenitores, tutores, a otros parientes o a terceras personas de aproximarse al menor y acercarse a su domicilio o centro educativo y a otros lugares que frecuente, con respeto al principio de proporcionalidad.

5. La medida de prohibición de comunicación con el menor, que impedirá a los progenitores, tutores, a otros parientes o a terceras personas establecer contacto escrito, verbal o visual por cualquier medio de comunicación o medio informático o telemático, con respeto al principio de proporcionalidad.

6. En general, las demás disposiciones que considere oportunas, a fin de apartar al menor de un peligro o de evitarle perjuicios en su entorno familiar o frente a terceras personas. Se garantizará por el Juez que el menor pueda ser oído en condiciones idóneas para la salvaguarda de sus intereses.

En caso de posible desamparo del menor, el juzgado comunicará las medidas a la entidad pública.

Todas estas medidas podrán adoptarse dentro de cualquier proceso civil o penal o bien en un expediente de jurisdicción voluntaria. 
me a lo establecido en los arts. 158 y $167^{3}$ del Código Civil, y podrá nombrar, si procediere, un defensor judicial o un administrador.

Otra de las manifestaciones de la acción tuitiva de la LJV respecto de personas con discapacidad es la inadmisión a trámite que establece el art. 139 de las peticiones de conciliación que se formulen en relación con los juicios en que estén interesadas las personas con capacidad modificada judicialmente para la libre administración de sus bienes.

Son numerosas, pues, las disposiciones que, en el marco de la jurisdicción voluntaria, hacen referencia a las personas con discapacidad, entre las que ocupan un nivel relevante por la vulnerabilidad las personas con capacidad modificada judicialmente, nueva denominación de los incapaces.

\section{Referencia especial a la intervención judicial en los internamientos urgentes en centros psiquiátricos}

Se discute si la ratificación judicial de los internamientos urgentes por razones psiquiátricas constituye o no un expediente de jurisdicción voluntaria.

Niega tal carácter Sáez González (2015), quien considera que en la actualidad no hay base legal para establecer vinculaciones entre los procedimientos de internamiento y los trámites de la jurisdicción voluntaria. Considera este autor que los trámites de internamiento constituyen un procedimiento especial, con entidad propia, que no es un apéndice de los procedimientos de incapacitación, aunque pueda darse una acumulación de los mismos en la práctica.

Otros, como González Poveda (1989) o más recientemente, Rodríguez Lainz (2016), consideran que el expediente de ratificación de internamiento involuntario, al igual que el de internamiento involuntario ordinario, participa sin duda de la naturaleza de procedimiento de jurisdicción voluntaria, toda vez que se ajusta perfectamente a los requisitos establecidos en el art. 1 de la LJV: como todo expediente de jurisdicción voluntaria, se trata de un procedimiento en el que se requiere la intervención de un órgano jurisdiccional para la tutela de derechos e intereses en materia de derecho civil, sin que exista controversia que deba sustanciarse en un proceso contencioso.

3 Art. 167 del Código Civil:

Cuando la administración de los progenitores ponga en peligro el patrimonio del hijo, el juez, a petición del propio hijo, del Ministerio Fiscal o de cualquier pariente del menor, podrá adoptar las medidas que estime necesarias para la seguridad y recaudo de los bienes, exigir caución o fianza para la continuación en la administración o incluso nombrar un administrador. 
Esta proximidad, al menos, de los expedientes de ratificación judicial de internamiento psiquiátrico urgente a las características de la jurisdicción voluntaria permite hacer una breve referencia a la problemática judicial surgida tras los últimos pronunciamientos del Tribunal Constitucional.

En Sentencia de STC 182/2015, de 7 de septiembre de 2015 (ROJ: STC 182/2015-ECLI:ES:TC:2015:182), sienta el Tribunal Constitucional los criterios para el cómputo del plazo de 72 horas que dispone el juez para para pronunciarse sobre la ratificación del internamiento involuntario comunicado por el director del centro psiquiátrico. Considera esta sentencia que desde que tiene lugar la comunicación por el centro hospitalario, la persona ingresada pasa a disposición del órgano judicial. Y que no es dable el reconocimiento de un lapso temporal intermedio - el tiempo que el asunto tarda en ingresar en el órgano judicial al que por reparto corresponde conocer-, que se ubica entre la comunicación del internamiento al Decanato y la operatividad del plazo judicial de 72 horas, pues la interpretación constitucionalmente adecuada del segundo párrafo del art. 763.1 LEC no admite solución de continuidad entre la comunicación del internamiento involuntario, por parte de la autoridad médica, y el inicio del plazo de 72 horas estatuido para la ratificación judicial de esa medida, ni permite intercalar plazos implícitos entre esos dos acontecimientos procesales.

La sentencia 13/2016, de 1 de febrero (ROJ: STC 13/2016-ECLI:ES: TC:2016:13), precisa que es el responsable de cada centro, quién permite que se materialice la privación de libertad de quien ingresa (o ya residía antes, por entrada voluntaria), si el centro dispone de médicos psiquiatras que puedan emitir informe que diagnostique el trastorno mental del afectado y motive en su caso la necesidad del internamiento, y si el centro cuenta con los equipos y recursos materiales (medicinas, etc.) que se requieran para el cuidado integral del interno y para iniciar el tratamiento terapéutico que precise. La norma del art. 763.1 LEC no contempla, por tanto — aclara el Tribunal Constitucional — que la comunicación al órgano judicial la efectúen quienes intervienen en un momento anterior al inicio del internamiento, como sucede con el traslado del afectado al centro, tarea ésta que puede corresponder en la casuística diaria a diversidad de personas, según las circunstancias (agentes policiales, personal de ambulancias, trabajadores sociales, o los propios parientes o conocidos de aquel). Y, por otro lado, considera el Tribunal Constitucional ineludible la existencia previa de un informe médico que justificara la medida de internamiento. Estima como una de las exigencias básicas en la fase extrajudicial (derivadas del respeto al derecho a la libertad personal que garantiza el art. 17.1 CE) para la validez del internamiento urgente no voluntario, la «existencia de un informe médico que acredite el trastorno psíquico justificante del internamiento inmediato: si bien el responsable del centro médico está 
facultado para tomar ab initio la decisión de internar a la persona, es evidente que esto se condiciona al hecho de que consten acreditadas en ese momento y tras su reconocimiento, la necesidad y proporcionalidad de la medida, de la que ha de informarse al interesado hasta donde le sea comprensible, debiendo quedar plasmado por escrito el juicio médico para su posterior control por la autoridad judicial». Por ello, reputa insuficiente la aportación con la solicitud de un informe del Samur social, informe propio de los profesionales que desarrollan sus actividades en el «equipo de internamientos involuntarios», que son trabajadores sociales, cuyo cometido no es examinar a la persona bajo «los conocimientos propios de la ciencia médica» [STC 141/2012, FJ 4 a)] y convencer al juez si es el caso de la necesidad del internamiento, sino que aplican el saber adquirido en su titulación (derecho, psicología, sociología, etc.) y la experiencia adquirida, para establecer en su trabajo diario si se está o no en presencia de una «emergencia social» (utilizando la terminología propia de estos trabajadores sociales), a fin de brindar una solución.

La sentencia 22/2016, de 15 de febrero (ROJ: STC 22/2016-ECLI:ES: TC:2016:22), hizo especial referencia al derecho del internado a contar con la asistencia jurídica de abogado y procurador y a la práctica de pruebas. Señala esta sentencia que para hacer efectivo este derecho a la asistencia jurídica, que resulta irrenunciable para su titular, el juez debe dirigirse al afectado; si es en la modalidad de internamiento urgente con la antelación necesaria dentro del plazo de las 72 horas en que ha de sustanciarse el procedimiento; antes o a más tardar durante el acto de exploración judicial del art. 763.3 LEC, a fin de informarle de la apertura del proceso y su finalidad, así como del derecho que tiene a una asistencia jurídica, pudiendo optar la persona por un abogado y procurador, sean de su confianza o designados por el juzgado de entre los del turno de oficio. Si nada manifiesta al respecto, bien porque no desea hacerlo, bien porque no es capaz de comprender lo que el juez le dice o de comunicar una respuesta, su representación y defensa deben ser asumidas por el fiscal actuante en la causa, que es lo que establece en ese caso el art. 758 LEC, al que se remite de manera expresa y sin reservas el art. 763.3 de la misma Ley. Sin embargo, de ser el fiscal el promotor de la medida de internamiento no podrá ser designado como su defensor, ordenando en tal supuesto el propio art. 758 LEC que se le designe un defensor judicial para que le represente; en este caso, se entiende, a los únicos efectos del procedimiento de internamiento. Dicho defensor judicial, que puede ser el representante legal del internado (si es menor de edad, quien ejerce la patria potestad; si es persona ya incapacitada por sentencia, su tutor) o sino quien designe el juzgado, nombrará entonces abogado y procurador o solicitará al juzgado su designación de entre los profesionales de oficio. 
La sentencia 50/2016, de 14 de marzo (ROJ: STC 50/2016-ECLI:ES: TC:2016:50), en la misma línea que la anterior, estima el recurso de amparo por vulneración del derecho a la asistencia jurídica, reconducido a lesión del derecho a la libertad del art. 17.1 de la Constitución, en un caso en el que ante la petición de la persona internada, formulada en el momento de su exploración por la magistrada, de que se le nombrara abogado y procurador, se ratificó el internamiento antes de que se designara a estos profesionales por los colegios respectivos y antes de que el Ministerio Fiscal emitiera informe sobre el internamiento.

Lasentencia34/2016, de 29 defebrero(ROJ:STC34/2016-ECLI:ES:TC: 2016:34), hace referencia a que no resulta posible hablar de la «regularización» de un internamiento involuntario que se prolonga durante días, semanas o meses sin autorización del juez, sea en un hospital, centro sociosanitario o en su caso residencia geriátrica. Sin embargo, ante la existencia de situaciones de donde se constata que una persona padece un trastorno psíquico con entidad suficiente para justificar una medida de internamiento, pero este no puede considerarse urgente al no constar que haya variado sustancialmente desde la fecha de su ingreso en el centro sociosanitario, considera que debía haberse iniciado un proceso de incapacitación y, en el seno del mismo, autorizar el internamiento como medida cautelar en un proceso de declaración de incapacidad ex art. 762 LEC.

Todas estas resoluciones inciden en un expediente judicial en el que la limitación rígida de los plazos para el pronunciamiento judicial genera importantes dificultades.

La recepción habitual en los decanatos de los juzgados de la comunicación del internamiento por el director del centro psiquiátrico, y las necesarias operaciones de reparto y traslado al juzgado competente consumen parte del plazo de 72 horas previsto legalmente para la ratificación o alzamiento del internamiento; plazo que, según la jurisprudencia del Tribunal Constitucional, se computa desde el ingreso de la primera comunicación en el ámbito judicial.

La necesidad de posibilitar la asistencia letrada efectiva al internado, implica emplear un tiempo en comunicar al letrado designado por el internado o sus representantes, o en lograr la designación de oficio por los colegios de abogados y procuradores, así como en permitir la intervención de estos profesionales. La citada sentencia 50/2016, señala al respecto que "para hacer efectivo este derecho a la asistencia jurídica, que resulta irrenunciable para su titular, el Juez debe dirigirse al afectado; si es en la modalidad de internamiento urgente con la antelación necesaria dentro del plazo de las 72 horas en que ha de sustanciarse el procedimiento; antes o a más tardar durante el acto de exploración judicial del art. 763.3 LEC, a fin de informarle de la apertura del proceso y su finalidad, así como del derecho que tiene a una asistencia 
jurídica, pudiendo optar la persona por un abogado y procurador, sean de su confianza o designados por el juzgado de entre los del turno de oficio».

Es preceptivo igualmente, según el apartado 3 del art. 763 de la LEC, el examen directo por el juez de la persona internada y oír el dictamen del facultativo designado por el mismo juez —informe pericial que requerirá de un tiempo mínimo en su elaboración-, a lo que puede unirse con carácter facultativo la práctica de otra prueba que se estime relevante, todo ello también en ese plazo máximo de 72 horas.

Aunque ese precepto no determina el momento de hacerlo, pero en todo caso antes del transcurso de ese plazo máximo de 72 horas, también debe darse audiencia al Ministerio Fiscal, lo que, como señala Rodríguez Lainz (op. cit.: 11) habitualmente en la práctica judicial se realiza una vez se han practicado todas las actuaciones previas y pruebas acordadas por el órgano judicial.

Y finalmente, antes del agotamiento del plazo de 72 horas, debe dictarse la resolución por el juez en relación con el internamiento, de la que necesariamente debe darse conocimiento al director del centro psiquiátrico antes del vencimiento de ese plazo, pues en caso contrario debería alzar el internamiento para no incurrir en una detención ilegal.

La descripción de todos estos trámites y la limitación estricta de tiempo para su conclusión, dada su relevancia en relación con los derechos constitucionales en juego, da una idea cabal de las dificultades a las que se enfrentan los juzgados competentes para ratificar los internamientos psiquiátricos urgentes. Si además tenemos en cuenta que el número de internamientos despachados durante el año 2015 ha ascendido, según datos de la Fiscalía Superior de Madrid, a 4818, el panorama resulta preocupante.

$\mathrm{El}$ interés de los discapacitados, que debe primar en todos los expedientes en los que estén interesados, obligaría quizá a reflexionar si la regulación actual y los plazos establecidos para el control judicial de los internamientos involuntarios son los adecuados.

Cierto es que el tiempo de privación de libertad que puede padecer el interesado antes del control judicial debe ser solamente el imprescindible.

Pero quizá una decisión tan trascendente como es la de mantener o alzar el internamiento forzoso de una persona por razones psiquiátricas debería estar precedida de un mayor grado de ponderación de las circunstancias y de garantías. El ejercicio efectivo del derecho de defensa del interesado difícilmente puede realizarse en la situación actual, lo que requeriría posibilitar realmente la intervención del abogado designado por el internado o su familia o del designado por el Colegio de Abogados, con tiempo suficiente para hacerse cargo de la situación de su defendido. La emisión del informe pericial por el facultativo designado por el juez requiere asimismo de un tiempo mínimo para entrevistar al internado, evaluar su estado y redactar con criterios 
rigurosos el dictamen correspondiente. El informe preceptivo del Ministerio Fiscal sólo puede hacerse - con el necesario rigor técnico - tras el examen de los datos suministrados en el expediente, con el tiempo correspondiente. El examen directo del internado por parte del juez — que también debe hacerse con la suficiente extensión - consume naturalmente parte del tiempo fijado legalmente. Y finalmente la decisión judicial exige ponderar en profundidad todas las circunstancias concurrentes, así como los informes emitidos y las alegaciones realizadas por la defensa del internado, con plasmación en una resolución fundada, que exige un tiempo para su redacción y que no puede ser fruto de un apresuramiento, y que además debe ser notificada a tiempo al director del centro que ha comunicado el internamiento involuntario.

La mimética aplicación en este ámbito de los criterios establecidos para la privación de libertad de personas en procedimientos penales puede no ser la adecuada.

El Tribunal Constitucional en las referidas sentencias sólo considera infranqueable, por exigencias constitucionales, el plazo de comunicación del internamiento al juzgado por parte del responsable del centro, ahora establecido en 24 horas y que nunca podría ir más allá de las 72 horas. Así lo recuerda la indicada Sentencia 182/2015:

la imposición de un límite temporal ha de venir impuesto por la norma legal de desarrollo, en este caso el ya citado art. 763 LEC, donde se señala que 'el responsable del centro en que se hubiere producido el internamiento deberá dar cuenta de éste al tribunal competente lo antes posible y, en todo caso, dentro del plazo de veinticuatro horas, a los efectos de que proceda a la preceptiva ratificación de dicha medida'. Plazo que el legislador actual o futuro no podría elevar en ningún caso más allá de las 72 horas, al resultar vinculante en este ámbito privativo de libertad la limitación que fija el art. 17.2 CE para las detenciones extrajudiciales, el cual, como tenemos declarado, no opera con carácter exclusivo en el orden penal (SSTC 341/1993, de 18 de noviembre, FJ 6; 179/2000, de 26 de junio, FJ 2; 53/2002, de 27 de febrero, FJ 6). Se trata, en todo caso, no de un plazo fijo sino máximo, que por ende no tiene que agotarse necesariamente en el supuesto concreto ni cabe agotarlo discrecionalmente. De este modo, la comunicación al tribunal habrá de efectuarla el director del centro en cuanto se disponga del diagnóstico que justifique el internamiento, sin más demora, siendo que las 24 horas empiezan a contar desde el momento en que se produce materialmente el ingreso del afectado en el interior del recinto y contra su voluntad.

Ahora bien, respecto del plazo de 72 horas establecido en el art. 763.1 LEC para la ratificación judicial de la medida de internamiento, el Tribunal Constitucional ha precisado que "la base constitucional de dicho plazo, al tratarse de una privación de libertad judicial, no reside en el art. 17.2 CE, sino 
el art. 17.1 CE, como tenemos ya dicho (SSTC 37/1996, de 11 de marzo, FJ 4; 180/2011, de 21 de noviembre, FJ 2)». Es decir, la determinación del plazo que debe disponer el juez para hacer ese pronunciamiento es de configuración legal — «en los casos y en la forma previstos en la ley», dice el art. 17.1 de la Constitución-, sin estar constreñido a las 72 horas que establece el apartado 2 de este art. 17 para la privación de libertad antes de poner a la persona a disposición judicial.

Concluyo, pues, con esta reflexión en voz alta: ¡cuál es la forma de proteger mejor los intereses de los discapacitados en estos casos: estableciendo un plazo tan exiguo o posibilitando una mayor ponderación de las circunstancias concurrentes en el internado forzoso, con real ejercicio de su defensa?

\section{BIBLIOGRAFÍA}

González Poveda (1989). La jurisdicción voluntaria. Doctrina y formularios, Navarra, 1989.

Rodríguez Lainz, J. (2016). El internamiento involuntario urgente en centro psiquiátrico en clave constitucional. Diario La Ley, 8763, 1.

Sáez González, J. (2015). La tutela judicial de los internamientos por razón de trastorno psíquico (Tratamiento posterior a la aprobación de la nueva Ley 15/2015, de 2 de julio, de la Jurisdicción Voluntaria). Madrid: Tecnos. 
